\title{
Spectroradiometric identification of phototrophic microorganisms in planktonic aquatic environments
}

\author{
Xavier Vila*, Carles A. Abella \\ Microbiology Section, Institute of Aquatic Ecology, University of Girona, Campus Montilivi, 17071 Girona, Spain
}

\begin{abstract}
An underwater spectroradiometer was used to analyse the spectral distribution of light in 41 lakes containing all of the main pigmentary groups of planktonic phototrophic microorganisms: eukaryotic phytoplankton, cyanobacteria, Chromatiaceae and the different pigmented groups of Chlorobiaceae. Results were processed to allow to the identification of phototrophic microorganisms through the calculation of light attenuation spectra at certain depth intervals from incident light spectra. These attenuation spectra allowed the detection of photosynthetic pigments present in the analysed depth intervals from their in vivo spectral characteristics. The pigmentary groups of microorganisms could then be differentiated by their respective compositions in photosynthetic pigments. Although this method is limited by both optical characteristics of the lakes (narrow available light spectral ranges) and composition of the microbial communities (pigments overlapping or too-low-density populations), this kind of in situ, in vivo spectroradiometric attenuation spectra can provide a fast qualitative alternative to other pigment analyses; it is especially useful for obtaining a first estimate of the community composition and vertical structure of the water column that can be relevant to the improve-

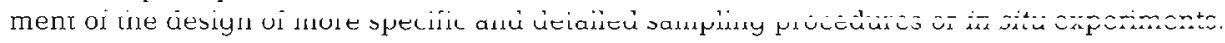

KEY WORDS: Spectroradiometry - Phototrophic bacteria Phytoplankton - Microbial ecology - Photosynthetic pigments . In vivo absorption spectra - Light quality · Light spectrum

\section{INTRODUCTION}

A high diversity of phototrophic microorganisms can be found in the planktonic environment of lakes. Eukaryotic phytoplankton, cyanobacteria, Chromatiaceae and different pigmented groups of Chlorobiaceae (or Green Sulfur Bacteria) are the main components of the phototrophic microbial community. Their populations can be separately found at different levels in stratified, stable communities (frequently metalimnetic communities) or mixed in turbulent, unstable epilimnia or hypolimnia. These microbial groups can be distinguished by their photosynthetic pigments and thus the analysis of the pigments present in water samples taken at different depths is the most usual method employed to identify and quantify the different populations of phototrophic microoganisms.

Bacterial pigments are usually extracted in organic solvents (e.g. acetone, ethanol, petroleum ether) and

\footnotetext{
•E-mail: ieaxvp@fc.udg.es
}

then analysed by spectrophotometry in the laboratory (Richards \& Thompson 1952, Takahashi \& Ichimura 1970, Jeffrey \& Humphrey 1975, Montesinos et al. 1983, Guerrero et al. 1985). Spectrophotometric absorption spectra from the extracts allow the identification of photosynthetic pigments present in the water samples from their characteristic spectral features. The composition of the phototrophic microbial community of each water sample can then be inferred from the pigments that have been detected, which can be attributed to different microorganisms. Pigment concentrations can also be calculated, using the appropriate formulae for each one. These calculations are based on the existence of a relationship between the pigment concentrations and the light absorbances at the wavelengths of maximum light absorption. Other methods for analysing pigment composition, which are specially used for phytoplankton analysis, are based on quantitativefilter measurements of light absorption (Yentsch 1962, Kishino et al. 1985), fluorescence emission spectra (Yentsch \& Yentsch 1979, Mitchell \& Kiefer 1984) or 
HPLC analysis (Hurley \& Watras 1991, Borrego \& Garcia-Gil 1994).

Spectroradiometers are habitually used to measure the in situ spectral distribution of incident light in aquatic environments, but they also allow qualitative identification of phototrophic microorganisms in these habitats. In this work, a spectroradiometer was used to analyse the spectral distribution of light in 41 lakes containing all pigmentary groups of phototrophic microorganisms. In vivo light attenuation spectra were calculated from incident light spectra at different depths, through the measurement of $K_{d}$ at different wavelengths, and allowed us identify the photosynthetic pigments present in the analysed depth intervals. The composition of the phototrophic microbial communities could also be inferred from the pigments that were spectroradiometrically detected.

\section{MATERIAL AND METHODS}

Spectroradiometry. Light measurements were performed using a battery-powered underwater spectroradiometer LI-1800 UW (Li-Cor Inc., Lincoln, NB) (Li-Cor 1984), which was composed of a submergible light detector and a portable LCD terminal (LI-1800-01), interconnected by a $30 \mathrm{~m}$ underwater I/O cable (2218 UW30). The submerged detection unit could be governed from the surface using the terminal. The detector system consisted of a cosine receptor, a wavelength separation system (a filter wheel and a holographic grating monochromator) and a silicon detector.

Photons at the visible and near-infrared spectral ranges ( 300 to $800 \mathrm{~nm}$ ) were registered as electronic signals, in $\mathrm{mV}$, that were automatically translated into irradiance data (incident radiant flux per area unit) using calibration and immersion effect correction files, and were recorded on an internal $256 \mathrm{~Kb}$ microcomputer, whose software allowed us to calculate integrated irradiance values for PAR and defined wave ranges and to perform different calculations. Data could be downloaded onto a computer using the LI-1800 UW terminal interface box and appropriate connection software. Irradiance values were obtained in quanta $\left(\mu \mathrm{E} \mathrm{m}^{-2} \mathrm{~s}^{-1} \mathrm{~nm}^{-1}\right)$ units for an adequate application of spectral light measurements to ecological and physiological studies related to phototrophic microorganisms.

Light attenuation spectra were calculated from spectral irradiance measurements on several depth intervals. They were obtained from the measurement of attenuation coefficients between successive depths, at different wavelengths between 300 and $800 \mathrm{~nm}$. For each wavelength, calculations followed the equation (Kirk 1994):

$$
K_{\mathrm{d}}\left(z_{1}, z_{2}\right)=\left[\ln E_{\mathrm{d}}\left(z_{1}\right)-\ln E_{\mathrm{d}}\left(z_{2}\right)\right]\left(z_{2}-z_{1}\right)^{-1}
$$

where $K_{\mathrm{d}}\left(z_{1,}, z_{2}\right)$ : attenuation coefficient at the depth interval $\left(z_{1}, z_{2}\right), E_{\mathrm{d}}\left(z_{1}\right)$ : inradiance at the shallowest limit $\left(z_{1}\right)$ of the interval $\left(z_{1}, z_{2}\right)$, and $E_{\mathrm{d}}\left(z_{2}\right)$ : irradiance at the deepest limit $\left(z_{2}\right)$ of the interval $\left(z_{1}, z_{2}\right)$.

Study lakes and light measurements. Light spectral measurements were performed from 1990 to 1994 in 41 water bodies (lakes or different basins from main lakes) of Europe and USA with depths ranging from 5 to $20 \mathrm{~m}$ and with different eutrophication levels (Table 1). Several European lakes were sampled at different moments of the seasonal cycle or at different years in order to get a higher diversity of conditions.

Table 1. Study lakes and their characteristics: depth of the sampling site (usually at the deepest point), maximum chl a concentration (an indication of the eutrophication level) and gilvin content

\begin{tabular}{|c|c|c|c|c|}
\hline Lake & Country & $\begin{array}{l}\text { Depth } \\
\text { (m) }\end{array}$ & $\begin{array}{c}\text { Chl a } \\
\left(\mu \mathrm{g} \mathrm{l}^{-1}\right)\end{array}$ & $\begin{array}{r}g_{440} \\
\left(\mathrm{~m}^{-1}\right)\end{array}$ \\
\hline Banyoles & Spain & & & \\
\hline Basin C-III & & 25 & $2-17$ & 0.5 \\
\hline Basin C-IV & & 18 & $6-20$ & 1.2 \\
\hline Basin C-VI & & 15 & $3-7$ & 0.4 \\
\hline Vilar & Spain & & & \\
\hline Basin V-I & & 9 & $15-43$ & - \\
\hline Basin V-II & & 9 & $27-66$ & 0.2 \\
\hline Sisó & Spain & 7 & $64-2722$ & 0.3 \\
\hline Coromina & Spain & 6 & $21-392$ & 2 \\
\hline Nou & Spain & 4 & 24 & 0.1 \\
\hline Cibollar & Spain & 9 & 11 & - \\
\hline Canyamel & Spain & 6 & 88 & - \\
\hline Buchensee & Germany & 11 & $44-51$ & - \\
\hline Schleinsee & Germany & 11 & $119-215$ & - \\
\hline Rotsee & Switzerland & 11 & 35 & - \\
\hline Cadagno & Switzerland & 13 & 68 & - \\
\hline Höllerersee & Austria & 17 & 87 & - \\
\hline Längsee & Austria & 19 & 22 & - \\
\hline Krötensee & Austria & 24 & 15 & - \\
\hline Wintergreen & MI (USA) & 7 & 277 & 0.2 \\
\hline Duck & MI (USA) & 4 & 101 & 1.6 \\
\hline Lefevre & MI (USA) & 15 & 102 & 0.9 \\
\hline Little Mill & MI (USA) & 10 & 160 & 0.3 \\
\hline Cassidy & MI (USA) & 10 & 56 & 0.4 \\
\hline Mud & MI (USA) & 7 & 81 & 1.6 \\
\hline Jones & MI (USA) & 13 & 203 & 1.2 \\
\hline Warner & MI (USA) & 17 & 26 & 0.01 \\
\hline Palmetier & MI (USA) & 11 & 85 & 0.3 \\
\hline Baker & MI (USA) & 8 & 21 & 1.6 \\
\hline Round & MI (USA) & 7 & 105 & 2.8 \\
\hline Peter & MI (USA) & 17 & 69 & 1.1 \\
\hline Paul & MI (USA) & 11 & 224 & 3.2 \\
\hline Fish & WI (USA) & 16 & 22 & 0.3 \\
\hline Wood & WI (USA) & 15 & 32 & 0.4 \\
\hline Mirror & WI (USA) & 13 & 73 & 0.8 \\
\hline Little Long & WI (USA) & 8 & 284 & 1.9 \\
\hline Silver & WI (USA) & & & \\
\hline Basin I & & 14 & 29 & 1.0 \\
\hline Basin II & & 8 & 169 & 0.5 \\
\hline Crystal & WI (USA) & 16 & 42 & 0.6 \\
\hline Minocqua & WI (USA) & 13 & 43 & 0.3 \\
\hline Sparkling & WI (USA) & 18 & 9 & 0.8 \\
\hline Trout Bog & WI (USA) & 7 & 21 & 4.0 \\
\hline Mary & WT (USA) & 16 & 110 & 5.7 \\
\hline
\end{tabular}


Light quality conditions in these lakes and the relationships between light quality and phototrophic microorganisms are described in Vila \& Abella (1994) and Vila et al. $(1996,1999)$.

Downward irradiance spectra were obtained at different positions of the water column in the study lakes, from the maximum depth with detectable light intensity to the surface. The spectroradiometer had been previously lowered to the bottom and then horizontally moved to avoid disturbances generated in the water column by the lowering process. Depth intervals between successive measurements ranged from $25 \mathrm{~cm}$ to $4 \mathrm{~m}$. Light spectra were measured around noon, with a spectral resolution of $2 \mathrm{~nm}$, as it was also done by other investigators (Pierson et al. 1990). Dim light situations (e.g. cloudy sky) were avoided when possible, in order to have the deepest light penetration in the water column, and measurements obtained under cloud intervals on partially cloudy days were rejected to elude irradiance changes during the spectral scanning process.

Identification of phototrophic microorganisms. The main pigmentary groups of phototrophic microorganisms found in the water column of the study lakes were identified by conventional analysis of their photosynthetic pigments and microscopic observation. For this purpose, water samples were collected at different depths using a special device designed for the study of

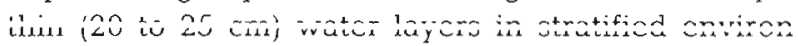
ments (Jørgensen et al. 1979) and were stored in dark bottles until analysis. Pigment analyses were performed by spectrophotometric determination (Guerrero et al. 1985) of their absorption spectra in acetone extracts using a Milton Roy Spectronic 3000 Diode Array, after filtering on cellulose nitrate filters of $0.45 \mu \mathrm{m}$ pore diameter, and by HPLC analysis (Borrego \& Garcia-Gil 1994) in a Waters 510 Pump and a Waters 996 Diode Array Detector provided with a Spherisorb C-18 column. Observation of centrifuged water samples under the optical microscope (Zeiss Axioskop, Zeiss, Oberkochen, Germany) was especially useful for discriminating between eukaryotic phytoplankton, redcoloured phycoerythrin-containing cyanobacteria and blue-coloured phycocyanin-enriched cyanobacteria.

Gilvin measurements. Humic substances or gilvin, the main soluble compounds in the water column of some lakes, were quantified with the $g_{440}$ parameter (Kirk 1994), obtained by spectrophotometrically measuring the absorbance at $440 \mathrm{~nm}$ of a pre-filtered (Millipore filter: $0.22 \mu \mathrm{m}$ pore) epilimnetic water sample.

\section{RESULTS}

Light attenuation spectra provided information about the main light absorption elements present in the water at the depth intervals where they were calculated. These elements could be related to the shape of the spectra and the position of the maximum attenuation wavelengths. Several examples of light attenuation spectra are presented in Fig. 1. The selective attenuation waveranges for different elements could be determined from these examples.

Effects of water and non-photosynthetic particulate compounds were found in all spectra, but they were dominant in the epilimnion of basin C.III in Banyoles Lake at 28 January 1991 (Fig. 1A), because of the low densities ( 1 to $2 \mu \mathrm{g} \mathrm{l}^{-1}$ chlorophyll a [chl a]) of the phytoplankton populations and low gilvin contents $\left(g_{440}<1 \mathrm{~m}^{-1}\right)$. A strong attenuation at long wavelengths (longer than $600 \mathrm{~nm}$ ) was related to water, as was already known (Kirk 1994), while the effects of non-photosynthetic particulate compounds were detected at short wavelengths (shorter than $500 \mathrm{~nm}$ ). The effects of soluble compounds manifested in lakes with high gilvin contents in a similar way to those of nonphotosynthetic particulate compounds. However, attenuation was stronger and reached up to $700 \mathrm{~nm}$ in the lakes where the highest gilvin contents $\left(>4 \mathrm{~m}^{-1}\right)$ were measured, e.g. Mary Lake and Trout Bog (Fig. 1B).

Photosynthetic microorganisms had different attenuation effects on light attenuation depending on the kind of pigments they contained. Chl $a$ in eukaryotic phritoplanlton and aranohantoria chnurad a roar icnlated attenuation maximum around 670 to $680 \mathrm{~nm}$ that was easily detected in eutrophic lakes, such as Schleinsee and Coromina Lake (Fig. 1C). A high attenuation related to carotenoids and Soret band of chl a was also found at short wavelengths (shorter than 500 to $550 \mathrm{~nm}$ ). Phycocyanin and phycoerythrin were also detected with cyanobacterial chl $a$. An attenuation maximum around 620 to $630 \mathrm{~nm}$ could be related to phycocyanin in lakes Cibollar and Mud (Fig. 1D), while a peak around 570 to $580 \mathrm{~nm}$ was attributed to phycoerythrin in Längsee (Fig. 1E). Both pigments were detected in Minocqua Lake (Fig. 1E).

Chromatiaceae were detected by the wide wave range of high light attenuation of their carotenoids, with maxima around $520-530 \mathrm{~nm}$ and a strong attenuation up to $600-650 \mathrm{~nm}$, as was shown in lakes Cadagno and Höllerersee (Fig. 1F). Bchl a was impossible to find, since its $Q_{y}$ absorption range is placed at very long wavelengths. Bchls $c, d$ and $e$ have absorption maxima around $740-750,720-730$ and $700-710 \mathrm{~nm}$, respectively. However, they were difficult to detect because these wavelengths are also strongly absorbed by water. Bchl $c$ could be found in Trout Bog (Fig. 1G), $\mathrm{Bchl} d$ in Coromina Lake (Fig. 1G) and Bchl $e$ in Basin C-IV of Banyoles Lake (Fig. 1H). The carotenoids of the green Chlorobiaceae and Chloronema species were difficult to differentiate from the algal carote- 

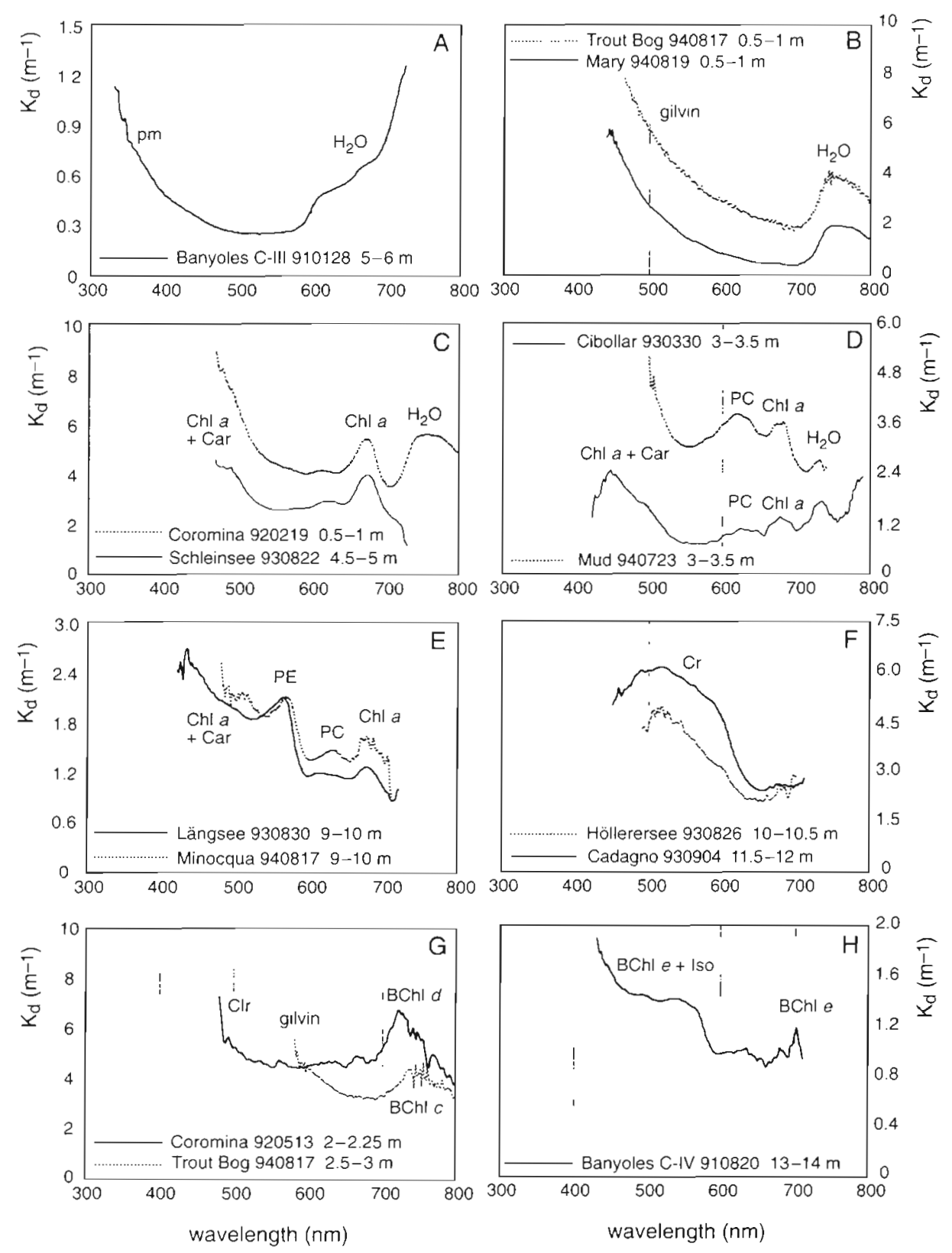

Fig. 1. Spectroradiometric light attenuation spectra, calculated as $K_{d}\left(\mathrm{~m}^{-1}\right)$ at different wavelengths, from water layers with dense populations of phototrophic microorganisms (see 'Results' for explanation). Lakes, dates and depths are indicated (date is given as yr, mo, d after lake name). Abbreviations refer to the light attenuation elements that could be identified: water $\left(\mathrm{H}_{2} \mathrm{O}\right)$, nonphotosynthetic particulate material (pm), humic substances (gilvin), chlorophyll a (chl a), algal carotenoids (Car), phycocyanin $(\mathrm{PC})$, phycoerythrin $(\mathrm{PE})$, Chromatiaceae carotenoids $(\mathrm{C} r)$, bacteriochlorophyll $c(\mathrm{Bchl} c)$, bacteriochlorophyll $d$ (Bchl $d)$, bacteriochlorophyll e (BChl e), clorobactene (CIr) and isorenieratene (Iso)

noids, but the wide absorption range of isorenieratene and Bchl e from the brown Chlorobiaceae could be detected between 500 and $600 \mathrm{~nm}$ in Banyoles Basin C-IV (Fig. 1H).

Vertical changes in the composition of stratified microbial communities could be detected by the analysis of spectroradiometric attenuation spectra. Consecutive spectra obtained at different depths changed in relation to the phototrophic microorganisms that dominated the community at each depth. When populations were mixed, the different microorganisms could be identified from the photosynthetic pigments detected by the spectroradiometer and the community composition could be successfully determined in most cases. In the examples 
shown in Fig. 2, the Sisó Lake community (Fig. 2A) was composed of eukaryotic phytoplankton (chl a), Chromatiaceae (carotenoids) and greencoloured Chlorobiaceae (Bchl $d$ ); the Wintergreen Lake community (Fig. 2B) contained eukaryotic phytoplankton (Chl a) and Chromatiacede (carotenoids); the Wood Lake community (Fig. 2C) was composed of cyanobacteria (phycoerythrin and phycocyanin) and brown-pigmented Chlorobiaceae (isorenieratene); and the Längsee community (Fig. 2D) contained phycoerythrin-containing cyanobacteria and Chromatiaceae. Spectrophotometric pigment analyses and microscopic observations confirmed these interpretations. Only Chromatiaceae in Wood Lake and brown-pigmented Chlorobiaceae in Sisó Lake could not be detected by the spectroradiometer.

\section{DISCUSSION}

Limitations to this method for the spectroradiometric laentuncation of pnotorropnic microorganisuls ale related both to the optical properties of the water column and to the composition of the microbial community. Optical properties of the lake determine the minimum and maximum wavelengths of the wave ranges available for the identification of photosynthetic pigments. Spectroradiometric attenuation spectra can only be obtained at wavelengths with enough light intensity to be detected by the instrument at the deeper position of the analysed depth interval. Light attenuation in the upper layers of the water column restrict the available wave range, usually limiting it to the central part of the spectrum. These limitations increase with depth due to the accumulative effect of light attenuation through the water column, but high gilvin contents or dense populations of phototrophic microorganisms can also have strong limiting effects on certain parts of the light spectrum even at shallow positions. Bchl $a$ is always out of the available light range, but also Bchls $c_{1} d$ and $e$ are often impaired by the previous light attenuation in the upper part of the water column. Brown Chlorobiaceae could only be detected in most cases by the presence of isorenieratene. Even chl a identification can be difficult at deep positions. Low light intensities can also prevent the calculation of attenuation spectra because of the high level of the noise irradiance registered at the whole spectrum range near the light detection limit.
Community composition can also make suitable identification of all their members difficult, since several photosynthetic pigments can overlap in the attenua-

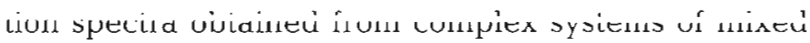
populations. The presence of dense populations of microorganisms that contain pigments with wide absorption wave ranges (e.g. Chromatiaceae carotenoids) can complicate the detection of other pigments in these waveranges. A minimum population density is also required for the detection of photosynthetic pigments: they must be concentrated enough to have a stronger attenuation effect than other elements. The use of narrow depth intervals is strongly recommended, especially when analysing metalimnetic communities: wide depth intervals can result in mixing the populations and thus more overlapping problems can arise.

Spectroradiometric attenuation spectra are especially useful for analysing multi-layered communities, where other methods requiring the pumping of water samples fail because of the thin microstratification and tend to mix water from consecutive microlayers. The spectroradiometer allows light scans to be made close to each other without disturbing the community, if populations are dense enough to allow photosynthetic pigments to be detected. Since spectroradiometric attenuation spectra are obtained in vivo, they allow the identification of pigments from their in vivo spectral features. Thus, certain pigments that are difficult to differentiate from their spectrophotometrical absorption characteristics in organic solvents (e.g. Bchl $c$ and 
chl a) can be discriminated by spectroradiometric analysis; this also allows the detection of pigments that are usually lost in spectrophotometric analyses because they are difficult to extract in organic solvents, such as phycobilins. However, spectroradiometric analysis cannot be considered as a quantitative method, and estimation of the absorption characteristics of phototrophic microbial populations is too vague to make it useful for optical limnology studies.

The main advantage of spectroradiometric identification of photosynthetic pigments is the rapidity in obtaining the results. Light scans and calculations can be quickly and easily done using appropriate worksheet software. If a portable computer is used instead of the portable LCD terminal, results can be obtained in situ in a few minutes. Anyway, this kind of procedure can be completed without performing the laboratory steps necessary for spectrophotometric, quantitative-filter or fluorimetric analyses. Extraction of water samples is also avoided. Although local disruption of the microstratification can result from a light-scanning profile, this is a less destructive process than pumping water and allows measuring or getting samples from the microbial community to be followed. Thus, this method can allow one to quickly obtain a first estimate of the composition and vertical structure of the phototrophic microbial community that can be relevant to the design of more specific and detailed subsequent sampling procedures or in situ experiments. With their inherent limitations, these kind of in situ, in vivo spectroradiometric attenuation spectra can provide a fast qualitative (but not quantitative) alternative to the conventional pigment analyses that can be especially useful in studies of microbial ecology. In a similar way, new in situ methods for determining absorption and beam attenuation spectra, such as WetLabs ac -9 sensors, allow one to measure spectral absorption coefficients and even to quantify them. The use of these methods in the future could improve the performances provided by the spectroradiometer by means of independence from solar conditions and attenuation by water, and thus it could be a better approach to the characterization of community composition than spectroradiometry.

Acknowledgements. We appreciate the collaboration of the colleagues at the Microbiology Section of the Institute of Aquatic Ecology, University of Girona, during the different sampling seasons. The anonymous reviewers are also acknowledged for their significant contributions to the improvement of the original manuscript. X.V. was the recipient of a doctoral scholarship from the Spanish Ministry of Education and Science (FP90-77910108). C.A.A. was supported by the research project NAT91-0708, from the Spanish Ministry of Education and Science. This is publication no. 153 of the Institute of Aquatic Ecology (University of Girona)

\section{LITERATURE CITED}

Borrego CM, Garcia-Gil LJ (1994) Separation of bacteriochlorophyl homologues from green photosynthetic sulfur bacteria by reversed-phase HPLC. Photosynth Res 41 $157-163$

Guerrero R, Montesinos E, Pedrós-Alió C, Esteve I, Mas J, van Gemerden H, Hofman PAG, Bakker JF (1985) Phototrophic sulfur bacteria in two spanish lakes: vertical distribution and liniting factors. Limnol Oceanogr 30:919-931

Hurley JP, Watras CJ (1991) Identification of bacteriochlorophylls in lakes via reverse-phase HPLC. Limnol Oceanogr 36:307-315

Jeffrey SW, Humphrey GF (1975) New spectrophotometric equations for determining chlorophylls $a_{1} b_{1} c_{1}$ and $c_{2}$ in higher plants, algae and natural phytoplankton. Biochem Physiol Pflanz 167:191-194

Jørgensen BB, Kuenen JG, Cohen Y (1979) Microbial transformations of sulfur compounds in a stratified lake (Solar Lake, Sinai). Limnol Oceanogr 24:799-822

Kirk JTO (1994) Light and photosynthesis in aquatic ecosystems. Cambridge University Press, Cambridge

Kishino M, Takahashi M, Okami M, Ichimura S (1985) Estimation of the spectral absorption coefficients of phytoplankton in the sea. Bull Mar Sci 37:634-642

Li-Cor (1984) LI-1800 UW underwater spectroradiometer instruction manual. Li-Cor Inc, Lincoln

Mitchell BG, Kiefer DA (1984) Determination of absorption and fluorescence excitation spectra for phytoplankton. In: Holm-Hansen O, Bolis L, Gilles R (eds) Marine phytoplankton and productivity. Springer-Verlag, New York, p $157-169$

Montesinos E, Abella CA, Guerrero R, Esteve I (1983) Ecology and physiology of the competition for light between Chlorobium limicola and Chlorobium phaeobacteroides in natural habitats. Appl Environ Microbiol 46:1007-1016

Pierson BK, Sands VM, Frederick JL (1990) Spectral irradiance and distribution of pigments in a highly layered marine microbial mat. Appl Environ Microbiol 56:2327-2340

Richards FA, Thompson TG (1952) The estimation and characterisation of plankton populations by pigment analyses. II. A spectrophotometric method for the estimation of plankton pigments. J Mar Res 11:156-172

Takahashi $M$, Ichimura $S$ (1970) Photosynthetic properties and growth of photosynthetic sulfur bacteria in lakes. Limnol Oceanogr 15:929-944

Vila X, Abella CA (1994) Effects of light quality on the physiology and the ecology of planktonic green sulfur bacteria in lakes. Photosynth Res 41:53-65

Vila X, Dokulil M, Garcia-Gil LJ, Abella CA, Borrego CM, BaOeras L (1996) Composition and distribution of phototrophic bacterioplankton in the deep communities of several central European lakes: the role of light quality. Arch Hydrobiol Spec Issues Adv Limnol 48:183-196

Vila X, Cristina XP, Abella CA, Hurley JP (1999) Effects of gilvin on the composition and dynamics of metalimnetic communities of phototrophic bacteria in freshwater NorthAmerican lakes. J Appl Bacteriol 85:138-150

Yentsch CS (1962) Measurement of visible light absorption by particulate matter in the ocean. Limnol Oceanogr 7:207-217

Yentsch CS, Yentsch CM (1979) Fluorescence spectral signatures: the characterization of phytoplankton populations by the use of excitation and emission spectra. J Mar Res $37: 471-483$

Submitted: September 9, 1998; Accepted: August 10, 1999

Proofs received from author(s): December 7, 1999 